\title{
An experimental and theoretical investigation into the electronically excited states of para-benzoquinone
}

D. B. Jones, P. Limão-Vieira, M. Mendes, N. C. Jones, S. V. Hoffmann, R. F. da Costa, M. T. do N. Varella, M.

H. F. Bettega, F. Blanco, G. García, O. Ingólfsson, M. A. P. Lima, and M. J. Brunger

Citation: The Journal of Chemical Physics 146, 184303 (2017);

View online: https://doi.org/10.1063/1.4982940

View Table of Contents: http://aip.scitation.org/toc/jcp/146/18

Published by the American Institute of Physics

\section{Articles you may be interested in}

Excited states from modified coupled cluster methods: Are they any better than EOM CCSD?

The Journal of Chemical Physics 146, 144104 (2017); 10.1063/1.4979078

A combined theoretical and experimental study of the valence and Rydberg states of iodopentafluorobenzene The Journal of Chemical Physics 146, 174301 (2017); 10.1063/1.4981919

CAP-XMCQDPT2 method for molecular electronic resonances

The Journal of Chemical Physics 146, 184107 (2017); 10.1063/1.4982950

Announcement: Top reviewers for The Journal of Chemical Physics 2016

The Journal of Chemical Physics 146, 100201 (2017); 10.1063/1.4978399

Theoretical study of photoinduced proton coupled electron transfer reaction using the non-perturbative hierarchical equations of motion method

The Journal of Chemical Physics 146, 184108 (2017); 10.1063/1.4982928

Two-photon absorption spectroscopy of stilbene and phenanthrene: Excited-state analysis and comparison with ethylene and toluene

The Journal of Chemical Physics 146, 174102 (2017); 10.1063/1.4982045

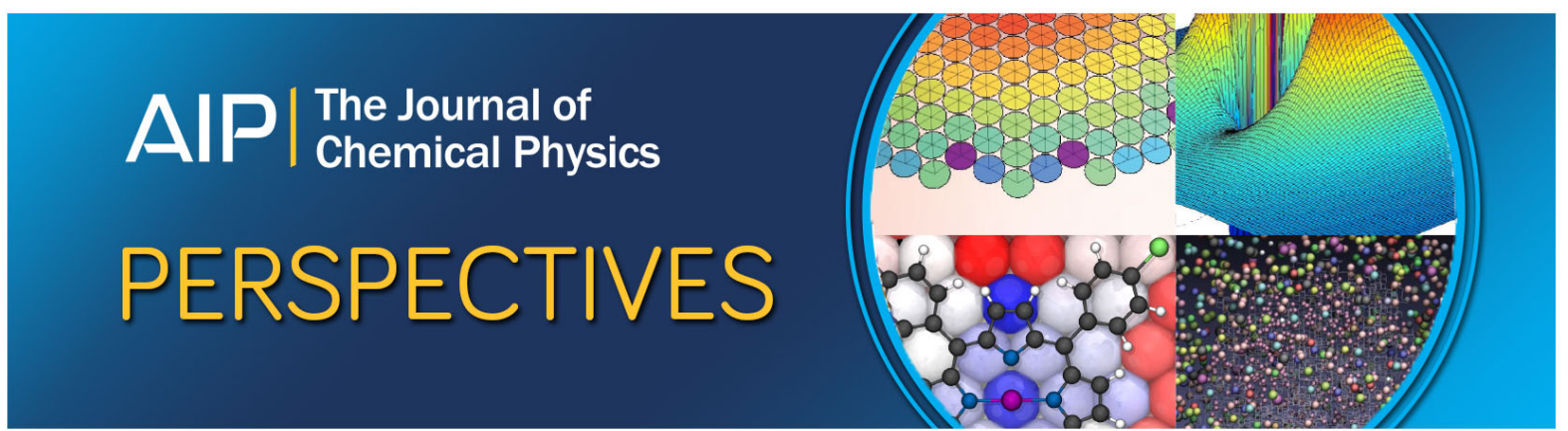




\title{
An experimental and theoretical investigation into the electronically excited states of para-benzoquinone
}

\author{
D. B. Jones, ${ }^{1, a)}$ P. Limão-Vieira, ${ }^{2, a)}$ M. Mendes, ${ }^{2}$ N. C. Jones, ${ }^{3}$ S. V. Hoffmann, ${ }^{3}$ \\ R. F. da Costa, ${ }^{4,5}$ M. T. do N. Varella, ${ }^{6}$ M. H. F. Bettega, ${ }^{7}$ F. Blanco, ${ }^{8}$ \\ G. García, ${ }^{9}$ O. Ingólfsson, ${ }^{10}$ M. A. P. Lima, ${ }^{4, a)}$ and M. J. Brunger ${ }^{1}$ \\ ${ }^{1}$ School of Chemical and Physical Sciences, Flinders University, GPO Box 2100, Adelaide, SA 5001, Australia \\ ${ }^{2}$ Laboratório de Colisões Atómicas e Moleculares, CEFITEC, Departamento de Física, Faculdade de Ciências \\ e Tecnologia, Universidade NOVA de Lisboa, 2829-516 Caparica, Portugal \\ ${ }^{3}$ ISA, Department of Physics and Astronomy, Aarhus University, Ny Munkegade, DK-8000 Aarhus C, Denmark \\ ${ }^{4}$ Instituto de Física "Gleb Wataghin," Universidade Estadual de Campinas, 13083-859 Campinas, \\ São Paulo, Brazil \\ ${ }^{5}$ Centro de Ciências Exatas, Departamento de Física, Universidade Federal do Espírito Santo, \\ 29075-910 Vitória, Espírito Santo, Brazil \\ ${ }^{6}$ Instituto de Física, Universidade de São Paulo, Rua do Matão 1731, 05508-090 São Paulo, São Paulo, Brazil \\ ${ }^{7}$ Departamento de Física, Universidade Federal do Paraná, CP 19044, 81531-990 Curitiba, Paraná, Brazil \\ ${ }^{8}$ Departamento de Física Atómica, Molecular y Nuclear, Universidad Complutense de Madrid, \\ Madrid E-28040, Spain \\ ${ }^{9}$ Instituto de Fisica Fundamental, CSIC, Serrano 113-Bis, 28006 Madrid, Spain \\ ${ }^{10}$ Science Institute and Department of Chemistry, University of Iceland, Dunhagi 3, 107 Reykjavik, Iceland
}

(Received 27 February 2017; accepted 21 April 2017; published online 9 May 2017)

\begin{abstract}
We report on a combination of experimental and theoretical investigations into the structure of electronically excited para-benzoquinone (pBQ). Here synchrotron photoabsorption measurements are reported over the 4.0-10.8 eV range. The higher resolution obtained reveals previously unresolved pBQ spectral features. Time-dependent density functional theory calculations are used to interpret the spectrum and resolve discrepancies relating to the interpretation of the Rydberg progressions. Electron-impact energy loss experiments are also reported. These are combined with elastic electron scattering cross section calculations performed within the framework of the independent atom modelscreening corrected additivity rule plus interference (IAM-SCAR + I) method to derive differential cross sections for electronic excitation of key spectral bands. A generalized oscillator strength analysis is also performed, with the obtained results demonstrating that a cohesive and reliable quantum chemical structure and cross section framework has been established. Within this context, we also discuss some issues associated with the development of a minimal orbital basis for the single configuration interaction strategy to be used for our high-level low-energy electron scattering calculations that will be carried out as a subsequent step in this joint experimental and theoretical investigation. Published by AIP Publishing. [http://dx.doi.org/10.1063/1.4982940]
\end{abstract}

\section{INTRODUCTION}

With an increasing demand for energy, global challenges relating to obtaining and storing energy in a sustainable manner are of significance. Understanding and mimicking nature might facilitate advances that may help address these challenges. Oxygenic photosynthesis, where $\mathrm{H}_{2} \mathrm{O}$ and $\mathrm{CO}_{2}$ are converted into sugars and $\mathrm{O}_{2}$, represents the primary energy conversion process on earth. ${ }^{1}$ Deepening our understanding of such photosynthetic pathways may therefore drive innovation in photovoltaics and photocatalysis, ${ }^{2}$ and also facilitate the creation of hybrid photo-bioelectrochemical technologies. ${ }^{3}$ Within the electron transport chain of photosynthesis and cellular respiration, quinones are an important molecular subunit as they are able to undergo reversible reduction. They are

\footnotetext{
a) Authors to whom correspondence should be addressed. Electronic addresses: darryl.jones@flinders.edu.au, plimaovieira@fct.unl.pt, and maplima@ifi.unicamp.br
}

therefore showing potential as a sustainable, low-cost material for energy applications. ${ }^{4,5}$ Quinone derivatives are known to form in the combustion of fuels, ${ }^{6}$ and their presence has been observed in air particulate samples within urban environments. A thorough understanding of quinone's electronic structure, and the role it plays in photon and electron chemistry, is therefore important in establishing innovative technologies that utilise quinone properties. This further improves our understanding of the sources and sinks, and potential environmental implications, of quinones and quinone-derivatives in the atmosphere.

para-benzoquinone ( $\mathrm{pBQ}, 1$,4-benzoquinone, $\mathrm{C}_{6} \mathrm{H}_{4} \mathrm{O}_{2}$, see Fig. 1) is the simplest quinone and has therefore served as a prototypical structure for understanding these complex chemical processes. The spectroscopy of $\mathrm{pBQ}$ has been controversial, owing to a large number of closely lying states. This has made quinone the subject of numerous investigations, with a review of its spectroscopy having been given by Itoh, ${ }^{7}$ and more recently by Ómarsson and Ingólfsson. ${ }^{8}$ There have also 


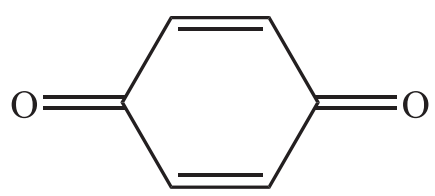

FIG. 1. Schematic representation of para-benzoquinone (pBQ,1,4-benzoquinone).

been photoelectron, ${ }^{9-12}$ Penning ionization, ${ }^{13}$ and matrix isolation ${ }^{14}$ studies to provide insights into the cationic structure of $\mathrm{pBQ}$, and resolve the energetic ordering of the closely lying 4outermost orbitals [the symmetric and asymmetric $\mathrm{O}(2 \mathrm{p})$ lone electron pairs, and two $\pi$-bonding orbitals]. It is now established that the orbital ordering is $4 \mathrm{~b}_{3 \mathrm{~g}}\left(\mathrm{n}_{\mathrm{O}}\right)>5 \mathrm{~b}_{2 \mathrm{u}}\left(\mathrm{n}_{\mathrm{O}}\right)>1 \mathrm{~b}_{1 \mathrm{~g}}$ $(\pi)>2 b_{3 u}(\pi)$. The gas-phase photoabsorption spectrum in the visible $^{15-17}$ and $\mathrm{UV}^{18-20}$ spectral regions has been extensively studied. In the vacuum ultraviolet (VUV) range, there is only a low resolution study by Brint et al., ${ }^{21}$ although the VUV spectra for $\mathrm{pBQ}$ have also been studied in various solutions. ${ }^{22}$ In the VUV region, $\mathrm{pBQ}$ showed an extensive Rydberg structure. The Rydberg structures of $\mathrm{pBQ}$ and substituted $\mathrm{pBQ}$ have been analysed by Brint and co-workers ${ }^{21,23}$ using a quantum defect approach, but they restricted their analysis to ketonic excitation from the HOMO. Pou-Amérigo et al. ${ }^{24}$ performed complete active space self-consistent field (CASSCF) theory and multiconfigurational second order perturbation theory (CASPT2) calculations for $\mathrm{pBQ}$. They then proposed alternative Rydberg assignments considering both ketonic and aromatic contributions. Weber and colleagues ${ }^{25}$ also performed calculations at the CASSCF and CASPT2 levels, with their results supporting the assertion that both ketonic and aromatic orbitals may participate in the pBQ Rydberg series. A high resolution re-investigation of the Rydberg behaviour of $\mathrm{pBQ}$, such as we report here, is therefore desirable. There have also been recent investigations into understanding the dynamics of photochemical processes in $\mathrm{pBQ} .^{26}$

From the electron scattering viewpoint, most studies have focused on electron attachment and resonances. ${ }^{27-29}$ Allan $^{30,31}$ has also performed transmission electron impact energy loss spectra measurements to gain insights into attachment and excitation processes. Further, the dynamics of the electron impact ionization of $\mathrm{pBQ}$ have been recently investigated. ${ }^{32}$

In the present contribution, we report a high resolution synchrotron photoabsorption spectrum of $\mathrm{pBQ}$. This is complemented by new electron energy loss spectra (EELSs) measurements. Intermediate-energy electron-impact differential scattering cross sections obtained using the independent atom model-screening corrected additivity rule plus interference (IAM-SCAR + I) method are also reported, and combined with a generalised oscillator strength (GOS) analysis. The experimental work is supplemented by theoretical calculations that are performed at the time-dependent density functional theory (TD-DFT) and full-single configuration interaction (FSCI) levels. This combination of experimental and theoretical techniques provides a contemporary re-investigation of the electronic structure of para-benzoquinone up to the first ionization potential. The higher resolution obtained in the present photoabsorption measurements, and the improved theoretical descriptions, allows us to observe previously unresolved features, and revise assignments relating to the interpretation of pBQ's spectroscopy.

As an extension of this work, we are also aiming to perform electron scattering cross section calculations for $\mathrm{pBQ}$ using the Schwinger multichannel method with pseudopotentials (SMCPPs). ${ }^{33}$ Here it is important to realise that this multichannel calculation for $\mathrm{pBQ}$ represents a significant computational challenge. With the quality of calculated electron scattering cross sections being inherently linked to how accurately the targets' electronic structure is described, ${ }^{34-37}$ the ability to determine a minimal orbital basis-single configuration interaction framework for the calculations, that is both computationally tractable and can appropriately describe the target structure, remains a crucial step towards a proper description of the scattering processes. An additional rationale for our current investigation is therefore to assess the feasibility of developing a minimum orbital basis for a single configuration interaction (MOB-SCI) strategy that is suitable for the foreshadowed sophisticated electron scattering calculations with the SMCPP method.

The outline of our paper is as follows. In Section II, we briefly describe the details of our experimental procedures and theoretical calculations, with our results being presented and discussed in Section III. Finally, in Section IV, some conclusions from this work are summarised.

\section{METHODS}

The high-resolution VUV photoabsorption spectrum of pBQ (Fig. 2(a)) was measured at the ASTRID2 storage ring at Aarhus University, Denmark, using the AU-UV beam line. The experimental setup has been described in detail elsewhere, ${ }^{38}$ with some modifications being reported recently. ${ }^{39}$ Briefly, the hot gas cell, which allows moderate (up to $80^{\circ} \mathrm{C}$ ) heating of a sample during measurement, is fitted with a heated 1 Torr full scale Baratron capacitance manometer (Setra model 774). To ensure that the data are free of any saturation effects, the absorption cross sections were measured at an appropriate pressure in the range $0.02-0.30$ mbar, with typical attenuations of less than $40 \%$. The light exits the absorption cell through a

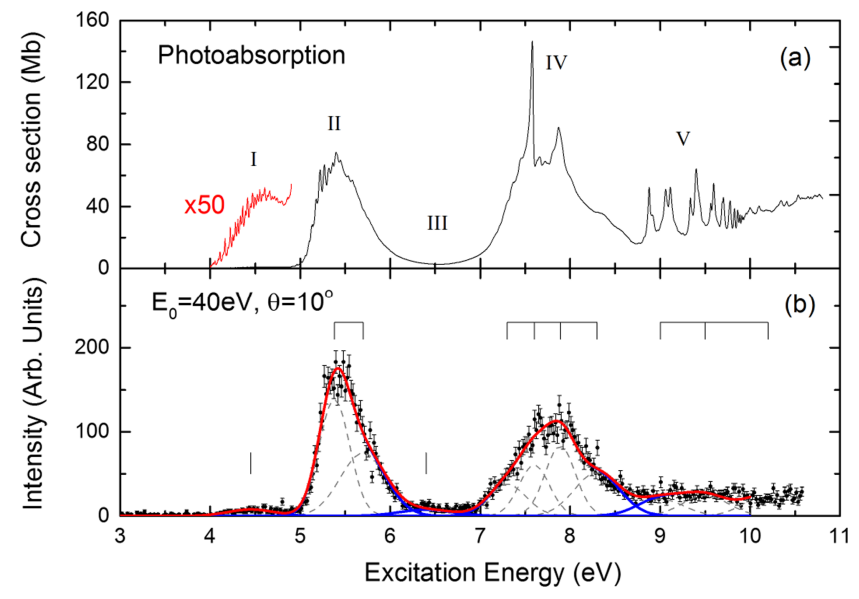

FIG. 2. (a) The measured photoabsorption spectrum and (b) high-resolution electron energy loss spectrum of pBQ (1,4-benzoquinone). The EELS spectrum was measured using an incident electron energy of $E_{0}=40 \mathrm{eV}$, while the scattering angle was $\theta=10^{\circ}$. Appropriate band labels (I-V) are also denoted. 
$\mathrm{MgF}_{2}$ window, which sets the lower limit of detectable light to $115 \mathrm{~nm}$. A small gap between the photo-multiplier tube (PMT) detector and the absorption cell is evacuated using a scroll pump for measurements below $200 \mathrm{~nm}$. Above $220 \mathrm{~nm}$, air is allowed into this gap to let oxygen absorb higher orders of light (at half the chosen wavelength) which may be passing through the cell. Therefore photoabsorption measurements can be safely performed with spectrally pure radiation in the wavelength range $115 \mathrm{~nm}-340 \mathrm{~nm}$. Absolute photoabsorption cross sections ( $\sigma$ in units of $\mathrm{Mb} \equiv 10^{-18} \mathrm{~cm}^{2}$ ) are obtained using the Beer-Lambert attenuation law $I_{t}=I_{0} \exp (-n \sigma x)$, where $I_{t}$ is the radiation intensity transmitted through the gas sample, $I_{0}$ is that through the evacuated cell, $n$ is the molecular number density of the sample gas, $\sigma$ is the absolute photoabsorption cross section, and $x$ is the absorption path length (15.5 $\mathrm{cm})$. ASTRID2 is operated in a "top-up" mode, keeping the stored electron beam current (and thus the intensity for a given wavelength) quasi-constant, which is achieved by adding small amounts of current to the storage ring to make up for the constant beam decay. This procedure causes the beam current to vary by about $3 \%$ during a scan, with this effect being compensated for by a normalization of the data to an accurately determined beam current. The accuracy of the cross section is estimated to be better than $\pm 5 \%$. Only when absorption by the sample is very weak $\left(I_{0} \approx I_{t}\right)$, does the error increase as a percentage of the measured cross section.

Electron energy loss spectra (EELSs) have been obtained on two electron-scattering spectrometers that have both been described previously. ${ }^{40,41}$ The first is a high-resolution spectrometer $[\Delta \mathrm{E} \sim 90 \mathrm{meV}(\mathrm{FWHM})]^{40}$ that operates at lowincident electron energies, while the second is a $(e, 2 e)$ coincidence spectrometer ${ }^{41}$ that is operated in an intermediateimpact energy, low-resolution EELS mode $[\Delta \mathrm{E} \sim 1.1 \mathrm{eV}$ (FWHM)]. To obtain electron energy loss spectra, the incident electron energy, $E_{0}$, and scattering angle, $\theta$, are fixed. We then record the number of electrons detected in the analyser, while continuously scanning over a range of scattered electron energies, $E_{s}$. The energy loss is then determined through,

$$
E_{\text {Loss }}=E_{0}-E_{s} .
$$

A high resolution EELS has been obtained (Fig. 2(b)) with an impact energy of $E_{0}=40 \mathrm{eV}$ and a small scattered electron angle $\theta=10^{\circ}$. At an intermediate impact energy, $E_{0}=250$ $\mathrm{eV}$, EELSs have also been obtained at discrete angles in the $\theta=4^{\circ}-50^{\circ}$ range. Inelastic differential cross sections (DCSs) are then derived from the measured inelastic to elastic scattering feature intensity ratio. Here the absolute scale of the elastic DCS is obtained through an independent atom modelscreening corrected additivity rule calculation ${ }^{42,43}$ with an interference term correction ${ }^{44}$ (IAM-SCAR + I). The IAMSCAR approach has typically produced reliable elastic scattering differential scattering cross sections at energies greater than $50 \mathrm{eV}$, and above $20 \mathrm{eV}$ in some cases, ${ }^{34,45-47}$ with the inclusion of the interference term expected to further improve the performance and expand the energy range where this approach is valid. ${ }^{35,44}$ We use this method here as to our knowledge no other experimental or theoretical elastic DCSs for pBQ are currently available at this intermediate impact energy. By employing the IAM-SCAR + I elastic scattering cross sections with the measured inelastic to elastic scattering intensity ratio, we are able to obtain DCS for the inelastic electron impact excitation processes. Our experience with the IAMSCAR approach ${ }^{48}$ suggests that the IAM-SCAR + I method should reproduce experimental elastic scattering DCS data to within $10 \%$, with this level of uncertainty in the elastic scattering data being incorporated into the reported DCS for electron impact excitation.

Generalised oscillator strengths (GOSs) are derived from the experimental DCSs using the standard formula. ${ }^{49}$ For the dipole allowed excitations, the experimental GOS as a function of the momentum transferred during the collision squared $\left(K^{2}\right)$ can be fitted with the analytic functional form proposed by Vriens. ${ }^{50}$ As the GOS converges to the optical oscillator strength (OOS) in the limit, $K^{2} \rightarrow 0$ a.u., the fitting functions are used to derive an experimental OOS. While the impact energy of $250 \mathrm{eV}$ is perhaps below that required to reach the optical limit, this approach has provided reasonable OOS for other molecules in the past. ${ }^{36,51-54}$ Full details and an overview of this method are contained in the recent review by Tanaka et al. ${ }^{55}$

In order to interpret our measured spectra, quantum chemical calculations were also performed. Here the geometry of pBQ was optimised at the B3LYP/aug-cc-pVDZ level. ${ }^{56-58}$ These calculations are undertaken with the quinone molecule being contained in the yz-plane, with the oxygen atoms located on the z-axis. This orientation (and state assignments) is consistent with recent investigations, ${ }^{24,25}$ but differs from earlier studies. ${ }^{18,19}$ Time-dependent density functional theory ${ }^{59,60}$ calculations were then performed at the B3LYP/aug-cc-pVDZ level to assist in the assignment of the photoabsorption spectrum. All of these calculations were performed in Gaussian 09. ${ }^{61}$

With a view to performing extensive electron scattering calculations within the minimal orbital basis for single configuration interaction (MOBSCI) framework, we first calculate the electronic structure of $\mathrm{pBQ}$ at the full single-excitation configuration interaction (FSCI) level of approximation. The FSCI calculations were performed using a $5 \mathrm{~s} 5 \mathrm{p} 2 \mathrm{~d}$ Cartesian Gaussian basis set, and also with an extended form of that basis that included additional diffuse p-type functions on the $\mathrm{C}$ and $\mathrm{O}$ atoms (5s6p2d). Here 49 states (26 triplets and 23 singlets) were obtained below $10 \mathrm{eV}$ with the smaller basis, which increased to 57 states ( 31 triplets and 26 singlets) below $10 \mathrm{eV}$ with the basis set extension. In this case, we observed that the calculated excitation energies for the low-lying states were quite similar for the two basis sets. As the excitation energy increases, the larger basis set increases the density of recovered states. This causes some deviations in the excitation energies, energetic ordering, and dominant orbital configurations contributions for those states, between the two FSCI calculations.

\section{RESULTS}

The measured synchrotron VUV photoabsorption spectrum and high resolution electron energy loss spectrum (EELS) are presented in Fig. 2. As the incident electron 
TABLE I. Experimental and selected theoretically derived excitation energies (eV) and optical oscillator strengths for the singlet states of $\mathrm{pBQ}$.

\begin{tabular}{|c|c|c|c|c|c|c|c|c|c|c|c|c|c|}
\hline \multirow[b]{2}{*}{ Expt. band } & \multirow{2}{*}{$\begin{array}{l}\text { EELS } \\
\text { Energy }\end{array}$} & \multicolumn{4}{|c|}{ TD-DFT } & \multicolumn{2}{|c|}{$\mathrm{FSCI} / 5 \mathrm{~s} 5 \mathrm{p} 2 \mathrm{~d}$} & \multicolumn{2}{|c|}{$\mathrm{FSCI} / 5 \mathrm{~s} 6 \mathrm{p} 2 \mathrm{~d}$} & \multicolumn{2}{|c|}{ CASPT $^{25}$} & \multicolumn{2}{|c|}{ Photoabsorption $^{21}$} \\
\hline & & State & Energy & $\mathrm{f}_{0}$ & Dominant configuration & Energy & $\mathrm{f}_{0}$ & Energy & $\mathrm{f}_{0}$ & Energy & $\mathrm{f}_{0}$ & Energy & $\mathrm{f}_{0}$ \\
\hline \multirow[t]{2}{*}{0} & & ${ }^{1} \mathrm{~B}_{1 \mathrm{~g}}$ & 2.49 & 0 & $\left(4 b_{3 g}\right)^{-1}\left(2 b_{2 g}\right)$ & 4.06 & 0.000 & 4.06 & 0.000 & 2.39 & $\ldots$ & & \\
\hline & & ${ }^{1} \mathrm{~A}_{\mathrm{u}}$ & 2.68 & 0 & $\left(5 b_{2 u}\right)^{-1}\left(2 b_{2 g}\right)$ & 4.25 & 0.000 & 4.25 & 0.000 & 2.43 & $\ldots$ & & \\
\hline I & 4.3 & ${ }^{1} \mathrm{~B}_{3 \mathrm{~g}}$ & 3.80 & 0 & $\left(1 b_{1 g}\right)^{-1}\left(2 b_{2 g}\right)$ & 5.15 & 0.000 & 5.15 & 0.000 & 4.01 & $\ldots$ & 4.091 & 0.005 \\
\hline \multirow[t]{2}{*}{ II } & $5.38-5.70$ & ${ }^{1} \mathrm{~B}_{1 \mathrm{u}}$ & 4.88 & 0.314 & $\left(2 b_{3 u}\right)^{-1}\left(2 b_{2 g}\right)$ & 6.38 & 1.070 & 6.38 & 1.070 & 5.09 & 0.636 & 5.083 & 0.44 \\
\hline & & ${ }^{1} \mathrm{~B}_{3 \mathrm{u}}$ & 5.38 & 0.001 & $\left(4 b_{3 g}\right)^{-1}\left(1 a_{u}\right)$ & & & & & 4.91 & 0.0004 & & \\
\hline III & 6.4 & ${ }^{1} \mathrm{~B}_{2 \mathrm{u}}$ & 6.90 & 0.014 & $\left(5 b_{2 u}\right)^{-1}\left(9 a_{g}\right)$ & & & & & 6.83 & 0.012 & & \\
\hline \multirow[t]{7}{*}{ IV } & 7.3-8.3 & ${ }^{1} \mathrm{~B}_{1 \mathrm{u}}$ & 7.05 & 0.076 & $\left(4 \mathrm{~b}_{3 \mathrm{~g}}\right)^{-1}\left(6 \mathrm{~b}_{2 \mathrm{u}}\right)$ & & & & & 7.07 & 0.026 & & \\
\hline & & ${ }^{1} \mathrm{~B}_{3 \mathrm{u}}$ & 7.15 & 0.006 & $\left(7 b_{1 u}\right)^{-1}\left(2 b_{2 g}\right)$ & 8.31 & 0.036 & 8.25 & 0.079 & & & & \\
\hline & & ${ }^{1} \mathrm{~B}_{1 \mathrm{u}}$ & 7.24 & 0.546 & $\left(1 b_{1 g}\right)^{-1}\left(1 a_{u}\right)$ & 8.63 & 0.626 & 8.59 & 0.611 & 7.18 & 0.693 & 7.067 & 0.81 \\
\hline & & ${ }^{1} \mathrm{~B}_{2 \mathrm{u}}$ & 7.49 & 0.248 & $\left(1 b_{1 g}\right)^{-1}\left(3 b_{3 u}\right)$ & 9.49 & 0.317 & 8.97 & 0.162 & & & & \\
\hline & & ${ }^{1} \mathrm{~B}_{3 \mathrm{u}}$ & 7.56 & 0.033 & $\left(2 b_{3 u}\right)^{-1}\left(9 a_{g}\right)$ & 8.43 & 0.100 & 9.11 & 0.016 & 7.76 & 0.037 & & \\
\hline & & ${ }^{1} \mathrm{~B}_{1 \mathrm{u}}$ & 8.02 & 0.019 & $\left(1 b_{3 u}\right)^{-1}\left(2 b_{2 g}\right)$ & & & & & & & & \\
\hline & & ${ }^{1} \mathrm{~B}_{1 \mathrm{u}}$ & 8.26 & 0.010 & $\left(5 b_{2 u}\right)^{-1}\left(5 b_{3 g}\right)$ & & & & & 7.81 & 0.044 & & \\
\hline \multirow[t]{8}{*}{ V } & $9-10.2$ & ${ }^{1} \mathrm{~B}_{2 \mathrm{u}}$ & 8.90 & 0.010 & $\left(1 b_{1 g}\right)^{-1}\left(4 b_{3 u}\right)$ & & & & & 8.39 & 0.018 & & \\
\hline & & ${ }^{1} \mathrm{~B}_{2 \mathrm{u}}$ & 9.03 & 0.033 & $\left(4 b_{3 g}\right)^{-1}\left(9 b_{1 u}\right)$ & & & & & & & & \\
\hline & & ${ }^{1} B_{2 u}$ & 9.35 & 0.055 & $\left(1 b_{2 g}\right)^{-1}\left(1 a_{u}\right)$ & & & & & & & & \\
\hline & & ${ }^{1} \mathrm{~B}_{1 \mathrm{u}}$ & 9.40 & 0.176 & $\left(4 b_{3 g}\right)^{-1}\left(8 b_{2 u}\right)$ & & & & & & & & \\
\hline & & ${ }^{1} \mathrm{~B}_{2 \mathrm{u}}$ & 9.53 & 0.095 & $\left(4 \mathrm{~b}_{3 \mathrm{~g}}\right)^{-1}\left(10 \mathrm{~b}_{1 \mathrm{u}}\right)$ & & & & & & & & \\
\hline & & ${ }^{1} \mathrm{~B}_{3 \mathrm{u}}$ & 9.58 & 0.066 & $\left(2 b_{3 u}\right)^{-1}\left(11 a_{g}\right)$ & & & & & & & & \\
\hline & & ${ }^{1} \mathrm{~B}_{1 \mathrm{u}}$ & 9.64 & 0.012 & $\left(4 b_{3 g}\right)^{-1}\left(9 b_{2 u}\right)$ & & & & & & & & \\
\hline & & ${ }^{1} \mathrm{~B}_{1 \mathrm{u}}$ & 9.66 & 0.012 & $\left(2 b_{3 u}\right)^{-1}\left(3 b_{2 g}\right)$ & & & & & & & & \\
\hline
\end{tabular}

energy is $40 \mathrm{eV}$, and the scattering angle is small $\left(\theta=10^{\circ}\right)$, the EELS is dominated by dipole allowed transitions, such that it strongly mimics the photoabsorption spectrum. It is clear that the photoabsorption resolution is superior to that obtained in the electron scattering experiment, and over the previous photoabsorption measurement by Brint et al. ${ }^{21}$ Qualitatively, the gross features observed in all the spectra are similar, although the lower resolution in the EELS leaves the intense Rydberg features seen in the photoabsorption spectrum unresolved. To help interpret our measured spectra, results from our quantum chemical calculations for the singlet-states are summarised in Table I. We have also calculated triplet state excitation energies, and these are contained in Table II.

TABLE II. Theoretical triplet state excitation energies (eV) of para-benzoquinone.

\begin{tabular}{|c|c|c|c|c|c|c|}
\hline \multirow{2}{*}{$\begin{array}{l}\text { Experimental } \\
\text { feature }\end{array}$} & \multirow{2}{*}{$\begin{array}{c}\text { Excitation } \\
\text { energy }\end{array}$} & \multicolumn{3}{|c|}{ TD-DFT } & \multirow{2}{*}{$\begin{array}{c}\text { FSCI/5s } 5 \mathrm{p} 2 \mathrm{~d} \\
\text { Energy }\end{array}$} & \multirow{2}{*}{$\begin{array}{c}\text { FSCI/5s } 6 \mathrm{p} 2 \mathrm{~d} \\
\text { Energy }\end{array}$} \\
\hline & & State & Energy & Dominant configuration & & \\
\hline \multirow[t]{4}{*}{ Band 0} & & ${ }^{3} \mathrm{~B}_{1 \mathrm{~g}}$ & 2.00 & $\left(4 b_{3 g}\right)^{-1}\left(2 b_{2 g}\right)$ & 3.37 & 3.37 \\
\hline & & ${ }^{3} \mathrm{~A}_{\mathrm{u}}$ & 2.17 & $\left(5 b_{2 u}\right)^{-1}\left(2 b_{2 g}\right)$ & 3.55 & 3.55 \\
\hline & & ${ }^{3} \mathrm{~B}_{1 \mathrm{u}}$ & 2.43 & $\left(2 b_{3 u}\right)^{-1}\left(2 b_{2 g}\right)$ & 2.44 & 2.44 \\
\hline & & ${ }^{3} \mathrm{~B}_{3 \mathrm{~g}}$ & 2.76 & $\left(1 b_{1 g}\right)^{-1}\left(2 b_{2 g}\right)$ & 2.71 & 2.71 \\
\hline \multirow[t]{2}{*}{ Band I } & 4.3 & ${ }^{3} \mathrm{~B}_{1 \mathrm{u}}$ & 4.88 & $\left(1 b_{1 g}\right)^{-1}\left(1 a_{u}\right)$ & 4.82 & 4.82 \\
\hline & & ${ }^{3} \mathrm{~A}_{\mathrm{g}}$ & 4.95 & $\left(1 b_{2 g}\right)^{-1}\left(2 b_{2 g}\right)$ & 4.65 & 4.65 \\
\hline \multirow[t]{5}{*}{ Band II } & $5.38-5.70$ & ${ }^{3} \mathrm{~B}_{3 \mathrm{u}}$ & 5.16 & $\left(4 b_{3 g}\right)^{-1}\left(1 a_{u}\right)$ & 7.56 & 7.56 \\
\hline & & ${ }^{3} \mathrm{~B}_{2 \mathrm{~g}}$ & 5.44 & $\left(5 \mathrm{~b}_{2 \mathrm{u}}\right)^{-1}\left(1 \mathrm{a}_{\mathrm{u}}\right)$ & 7.40 & 7.40 \\
\hline & & ${ }^{3} \mathrm{~B}_{1 \mathrm{~g}}$ & 5.60 & $\left(3 b_{3 g}\right)^{-1}\left(2 b_{2 g}\right)$ & 7.42 & 7.42 \\
\hline & & ${ }^{3} \mathrm{~B}_{3 \mathrm{~g}}$ & 5.78 & $\left(2 b_{3 u}\right)^{-1}\left(1 a_{u}\right)$ & 7.74 & 7.73 \\
\hline & & ${ }^{3} \mathrm{~A}_{\mathrm{u}}$ & 5.92 & $\left(4 b_{3 g}\right)^{-1}\left(3 b_{3 u}\right)$ & & \\
\hline \multirow[t]{6}{*}{ Band III } & 6.4 & ${ }^{3} \mathrm{~B}_{2 \mathrm{~g}}$ & 6.14 & $\left(8 a_{g}\right)^{-1}\left(2 b_{2 g}\right)$ & & \\
\hline & & ${ }^{3} \mathrm{~B}_{1 \mathrm{~g}}$ & 6.29 & $\left(5 b_{2 u}\right)^{-1}\left(3 b_{3 u}\right)$ & 7.92 & 7.89 \\
\hline & & ${ }^{3} \mathrm{~B}_{1 \mathrm{u}}$ & 6.42 & $\left(1 b_{3 u}\right)^{-1}\left(2 b_{2 g}\right)$ & & \\
\hline & & ${ }^{3} \mathrm{~B}_{3 \mathrm{u}}$ & 6.53 & $\left(7 b_{1 u}\right)^{-1}\left(2 b_{2 g}\right)$ & & \\
\hline & & ${ }^{3} \mathrm{~B}_{3 \mathrm{~g}}$ & 6.64 & $\left(4 b_{3 g}\right)^{-1}\left(9 a_{g}\right)$ & & \\
\hline & & ${ }^{3} \mathrm{~B}_{2 \mathrm{u}}$ & 6.76 & $\left(1 b_{1 g}\right)^{-1}\left(3 b_{3 u}\right)$ & 8.63 & 8.58 \\
\hline
\end{tabular}




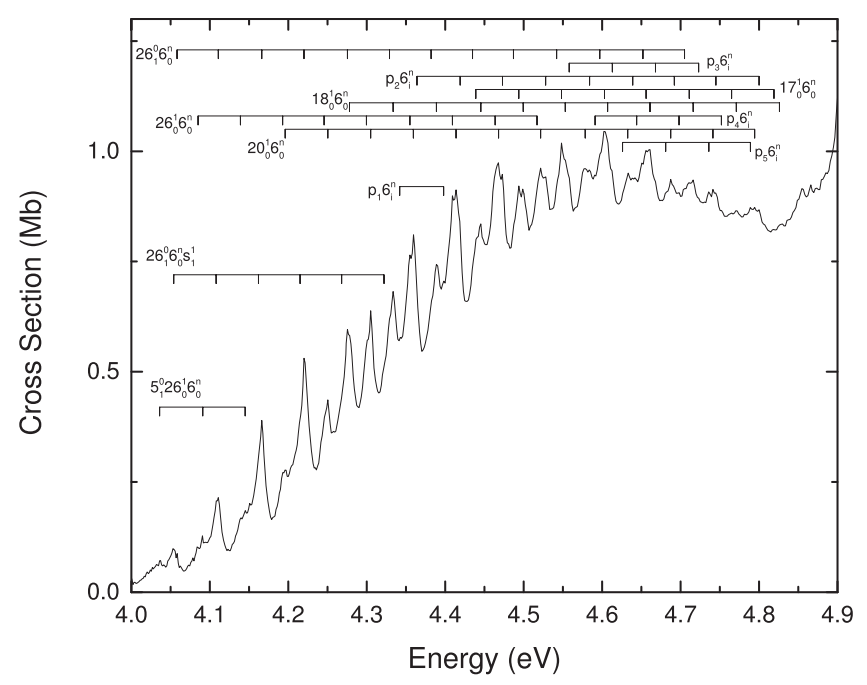

FIG. 3. Photoabsorption spectrum of $\mathrm{pBQ}$ in the $4.0-4.9 \mathrm{eV}$ energy region (Band I).

\section{A. Low lying electronic states $(<4.0 \mathrm{eV})$}

pBQ has a number of low-lying singlet and triplet states. These states are not examined experimentally in the present investigation, but we briefly comment on them to provide a complete overview on the electronic structure of $\mathrm{pBQ}$ up to the first ionization potential. In the case of the singlet states, transitions to these states from the ground state are symmetryforbidden, but can gain some intensity through vibronic coupling. These states lie in the visible region and have been studied previously. ${ }^{15}$ Excitation to these states is particularly weak, and we do not observe any significant intensity in the EELS measured for $E_{0}=40 \mathrm{eV}$ and $\theta=10^{\circ}$. Constant residual-energy electron impact energy loss spectra have been measured by Allan, ${ }^{30}$ with these spectra revealing the existence of low-lying triplet states with excitation energy of $\sim 3 \mathrm{eV}$. Our TD-DFT calculations support the existence of 4 low-lying triplet states in this region. The FSCI calculations also support 4 low-lying triplet states existing in this band.

TABLE III. Prominent experimental features observed in the photoabsorption spectrum in the 4.0-4.9 eV range, Band I. Here we tentatively assign vibrational progressions based on the vibrational analysis of the ground and excited states performed by Weber et al., ${ }^{25}$ using the origin $4.067 \mathrm{eV}$ proposed by Trommsdorff; ${ }^{19}$ (w) weak feature; (s) shoulder; (b) broad. Progressions with unclear origins are labeled $p_{i}$. Unassigned sequence transitions are labelled $s_{1}^{1}$. Ground state vibrational frequencies: $v_{5}\left(a_{g}\right)=0.095 \mathrm{eV} ; v_{6}\left(a_{g}\right)=0.055 \mathrm{eV} ; v_{17}\left(b_{2 u}\right)=0.380 \mathrm{eV}$; $v_{18}\left(b_{2 u}\right)=0.197 \mathrm{eV} ; v_{20}\left(b_{2 u}\right)=0.132 \mathrm{eV} ; v_{26}\left(b_{3 u}\right)=0.011 \mathrm{eV}$.

\begin{tabular}{|c|c|c|c|c|c|}
\hline Energy (eV) & Assignment & Energy $(\mathrm{eV})$ & Assignment & Energy $(\mathrm{eV})$ & Assignment \\
\hline 4.036 & $5_{1}^{0} 26_{0}^{1} 6_{0}^{1}$ & 4.409 & $26_{0}^{1} 6_{0}^{6}$ & 4.668 & $p_{3} 6_{i}^{n+3}$ \\
\hline 4.054 & $26_{1}^{0} 6_{0}^{0} s_{1}^{1}$ & 4.414 & $20_{0}^{1} 6_{0}^{4}$ & 4.681 & $p_{5} 6_{i}^{n+1}$ \\
\hline 4.058 & $26_{1}^{0} 6_{0}^{0}$ & $4.419(\mathrm{~s})$ & $p_{2} 6_{i}^{n+1}$ & 4.687 & $20_{0}^{1} 6_{0}^{9}$ \\
\hline 4.085 & $26_{0}^{1} 6_{0}^{0}$ & $4.435(\mathrm{~s})$ & $26_{1}^{0} 6_{0}^{7}$ & 4.692(bs) & $p_{2} 6_{i}^{n+6}$ \\
\hline 4.091 & $5_{1}^{0} 26_{0}^{1} 6_{0}^{2}$ & 4.439 & $17_{0}^{1} 6_{0}^{0}$ & 4.698 & $p_{4} 6_{i}^{n+2}$ \\
\hline 4.108 & $26_{1}^{0} 6_{0}^{1} s_{1}^{1}$ & 4.445 & $18_{0}^{1} 6_{0}^{3}$ & $4.705(\mathrm{bs})$ & $26_{1}^{0} 6_{0}^{12}$ \\
\hline 4.111 & $26_{1}^{0} 6_{0}^{1}$ & $4.464(\mathrm{~s})$ & $26_{0}^{1} 6_{0}^{7}$ & 4.711(b) & $17_{0}^{1} 6_{0}^{5}$ \\
\hline 4.139 & $26_{0}^{1} 6_{0}^{1}$ & 4.468 & $20_{0}^{1} 6_{0}^{5}$ & 4.716 & $18_{0}^{1} 6_{0}^{8}$ \\
\hline 4.145 & $5_{1}^{0} 26_{0}^{1} 6_{0}^{3}$ & 4.473 & $p_{2} 6_{i}^{n+2}$ & 4.723 & $p_{3} \sigma_{i}^{n+4}$ \\
\hline 4.151 & & 4.481 & & 4.736 & $p_{5} 6_{i}^{n+2}$ \\
\hline $4.162(s)$ & $26_{1}^{0} 6_{0}^{2} s_{1}^{1}$ & $4.487(\mathrm{~s})$ & $26_{1}^{0} 6_{0}^{8}$ & 4.741 & $20_{0}^{1} 6_{0}^{10}$ \\
\hline 4.166 & $26_{1}^{0} 6_{0}^{2}$ & 4.494 & $17_{0}^{1} 6_{0}^{1}$ & 4.745 & $p_{2} 6_{i}^{n+7}$ \\
\hline 4.193 & $26_{0}^{1} 6_{0}^{2}$ & 4.499 & $18_{0}^{1} 6_{0}^{4}$ & 4.752 & $p_{4} 6_{i}^{n+3}$ \\
\hline 4.196 & $20_{0}^{1} 6_{0}^{0}$ & $4.517(\mathrm{~s})$ & $26_{0}^{1} 6_{0}^{8}$ & $4.765(b)$ & $17_{0}^{1} 6_{0}^{6}$ \\
\hline $4.204(\mathrm{~s})$ & & 4.522 & $20_{0}^{1} 6_{0}^{6}$ & 4.771 & $18_{0}^{1} 6_{0}^{9}$ \\
\hline $4.215(\mathrm{~s})$ & $26_{1}^{0} 6_{0}^{3} s_{1}^{1}$ & 4.528 & $p_{2} 6_{i}^{n+3}$ & 4.782 & \\
\hline 4.220 & $26_{1}^{0} 6_{0}^{3}$ & $4.542(\mathrm{~s})$ & $26_{1}^{0} 6_{0}^{9}$ & 4.789 & $p_{5} 6_{i}^{n+3}$ \\
\hline $4.246(\mathrm{~s})$ & $26_{0}^{1} 6_{0}^{3}$ & 4.548 & $17_{0}^{1} 6_{0}^{2}$ & 4.794 & $20_{0}^{1} 6_{0}^{11}$ \\
\hline 4.250 & $20_{0}^{1} 6_{0}^{1}$ & 4.553 & $18_{0}^{1} 6_{0}^{5}$ & 4.800 & $p_{2} 6_{i}^{n+8}$ \\
\hline $4.268(\mathrm{~s})$ & $26_{1}^{0} 6_{0}^{4} s_{1}^{1}$ & 4.558 & $p_{3} 6_{i}^{n}$ & 4.819 & $17_{0}^{1} 6_{0}^{7}$ \\
\hline 4.275 & $26_{1}^{0} 6_{0}^{4}$ & 4.578(b) & $20_{0}^{1} 6_{0}^{7}$ & $4.826(\mathrm{bs})$ & $18_{0}^{1} 6_{0}^{10}$ \\
\hline 4.278 & $18_{0}^{1} 6_{0}^{0}$ & 4.584 & $p_{2} 6_{i}^{n+4}$ & 4.830 & \\
\hline $4.300(\mathrm{~s})$ & $26_{0}^{1} 6_{0}^{4}$ & 4.591 & $p_{4} 6_{i}^{n}$ & 4.837(b) & \\
\hline 4.305 & $20_{0}^{1} 6_{0}^{2}$ & 4.597 & $26_{1}^{0} 6_{0}^{10}$ & 4.843 & \\
\hline $4.322(\mathrm{~s})$ & $26_{1}^{0} 6_{0}^{5} s_{1}^{1}$ & 4.603 & $17_{0}^{1} 6_{0}^{3}$ & $4.849(\mathrm{~s})$ & \\
\hline $4.329(\mathrm{~s})$ & $26_{1}^{0} 6_{0}^{5}$ & 4.607 & $18_{0}^{1} 6_{0}^{6}$ & $4.855(b)$ & \\
\hline 4.334 & $18_{0}^{1} 6_{0}^{1}$ & $4.613(\mathrm{~s})$ & $p_{3} 6_{i}^{n+1}$ & $4.866(b)$ & \\
\hline $4.342(w)$ & $p_{1} 6_{i}^{n}$ & $4.626(\mathrm{~s})$ & $p_{5} 6_{i}^{n}$ & 4.874 (b) & \\
\hline 4.355 & $26_{0}^{1} 6_{0}^{5}$ & 4.633 & $20_{0}^{1} 6_{0}^{8}$ & $4.879(\mathrm{~s})$ & \\
\hline 4.360 & $20_{0}^{1} 6_{0}^{3}$ & 4.639(b) & $p_{2} 6_{i}^{n+5}$ & 4.885 & \\
\hline $4.364(\mathrm{~s})$ & $p_{2} 6_{i}^{n}$ & $4.644(b)$ & $p_{4} 6_{i}^{n+1}$ & & \\
\hline $4.383(\mathrm{~s})$ & $26_{1}^{0} 6_{0}^{6}$ & $4.652(\mathrm{~s})$ & $26_{1}^{0} 6_{0}^{11}$ & & \\
\hline 4.389 & $18_{0}^{1} 6_{0}^{2}$ & 4.656 & $17_{0}^{1} 6_{0}^{4}$ & & \\
\hline $4.398(w)$ & $p_{1} \sigma_{i}^{n+1}$ & 4.661 & $18_{0}^{1} 6_{0}^{7}$ & & \\
\hline
\end{tabular}




\section{B. Band I (4.0-4.9 eV and 310-253 nm)}

The photoabsorption spectrum in the 4.0-4.9 eV energy region is presented in Figure 3, and the proposed assignments are summarised in Table III. The key features within this band have been studied by Sadô ${ }^{18}$ and Trommsdorff and colleagues. ${ }^{19,20}$ The $(0-0)$ origin band is not pronounced in the spectrum, although through a consideration of chloro-quinone derivatives, Trommsdorff ${ }^{19}$ has estimated the $\mathrm{pBQ}$ origin to be at $4.067 \mathrm{eV}$. The most comprehensive assignments by Sadô were based on an assumption that two distinct electronic transitions existed within this region; however, Trommsdorff ${ }^{19}$ proposed that the second progression was a sequence band. Our TD-DFT and CI calculations only support a single ${ }^{1} \mathrm{~B}_{3 \mathrm{~g}}$ state, involving a $\pi \pi^{*}$ excitation, in this region. This excitation is dipole forbidden, but can become accessible through vibronic coupling. The present assignments are therefore based on multiple vibrational progressions of a $v_{6}$-mode, built on sequence, hot and combination bands. The absence of a well-established origin makes definitive assignments of each progression to specific spectral features difficult, and so, many spectral progressions are left unassigned. It is important to note that the low-residual energy EELS ${ }^{30}$ suggests that triplet states are also located in this region. Here our TD-DFT calculations suggest that two triplet states $\left({ }^{3} B_{1 u}\right.$ and $\left.{ }^{3} A_{g}\right)$ may occur within this band.

\section{Band II (4.9-5.9 eV and 253-210 nm)}

The photoabsorption spectrum of Band II is presented in Figure 4, with the present spectral assignments being contained in Table IV. In this Band II, we have intensity from a dipole allowed transition to a ${ }^{1} \mathrm{~B}_{1 \mathrm{u}}$ state, with this transition corresponding to a $\pi \pi^{*}$ excitation. The promotion of an electron from a bonding to an anti-bonding orbital should significantly alter the equilibrium geometry of the excited ${ }^{1} \mathrm{~B}_{1 \mathrm{u}}$ state. Those variations to the bonding network are also expected to alter the vibrational mode frequencies. This creates the complex progressions observed in the photoabsorption spectrum, and further complicates the interpretation of this spectral

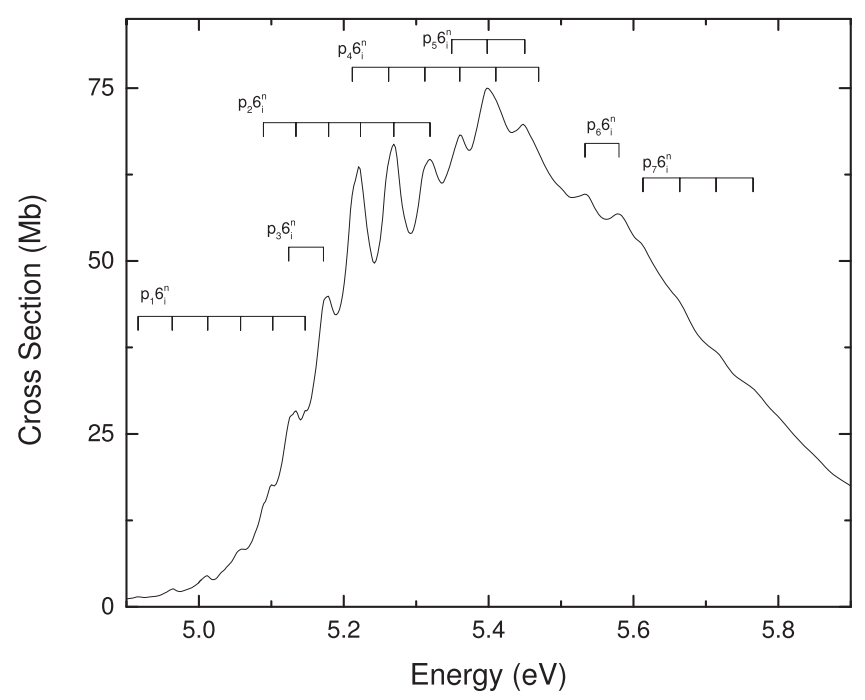

FIG. 4. Photoabsorption spectrum of $\mathrm{pBQ}$ in the 4.9-5.9 $\mathrm{eV}$ energy region (Band II).
TABLE IV. Prominent experimental features observed in the photoabsorption spectrum in the 4.9-5.9 eV range, Band II (see also Figure 4); (w) weak feature; (s) shoulder; (b) broad. Progressions with unclear origins are labeled $p_{i}$.

\begin{tabular}{lc}
\hline \hline Energy (eV) & Assignment \\
\hline 4.903 & \\
4.916 & $p_{1} 6_{i}^{n}$ \\
$4.920(\mathrm{~s})$ & \\
4.935 & \\
$4.952(\mathrm{~s})$ & \\
4.963 & $p_{1} 6_{i}^{n+1}$ \\
$4.984(\mathrm{w})$ & \\
5.001 & \\
5.012 & $p_{1} 6_{i}^{n+2}$ \\
5.058 & $p_{1} 6_{i}^{n+3}$ \\
5.089 & $p_{2} 6_{i}^{n}$ \\
5.102 & $p_{1} 6_{i}^{n+4}$ \\
5.124 & $p_{3} 6_{i}^{n}$ \\
5.134 & $p_{2} 6_{i}^{n+1}$ \\
5.147 & $p_{1} 6_{i}^{n+5}$ \\
5.172 & $p_{3} 6_{i}^{n+1}$ \\
5.179 & $p_{2} 6_{i}^{n+2}$ \\
5.212 & $p_{4} 6_{i}^{n}$ \\
5.223 & $p_{2} 6_{i}^{n+3}$ \\
5.262 & $p_{4} 6_{i}^{n+1}$ \\
5.269 & $p_{2} 6_{i}^{n+4}$ \\
5.312 & $p_{4} 6_{i}^{n+2}$ \\
5.319 & $p_{2} 6_{i}^{n+5}$ \\
$5.349(\mathrm{~s})$ & $p_{5} 6_{i}^{n}$ \\
5.360 & $p_{4} 6_{i}^{n+3}$ \\
5.386 & $p_{5} 6_{i}^{n+1}$ \\
5.398 & $p_{4} 6_{i}^{n+4}$ \\
5.410 & $p_{5} 6_{i}^{n+2}$ \\
5.447 & $p_{4} 6_{i}^{n+5}$ \\
$5.469(\mathrm{~b})$ & $p_{6} 6_{i}^{n}$ \\
$5.533(\mathrm{~b})$ & $p_{6} 6_{i}^{n+1}$ \\
$5.580(\mathrm{~b})$ & $p_{7} 6_{i}^{n}$ \\
$5.613(\mathrm{~b})$ & $p_{7} 6_{i}^{n+1}$ \\
$5.664(\mathrm{~b})$ & $p_{7} 6_{i}^{n+2}$ \\
$5.714(\mathrm{~b})$ & $p_{7} 6_{i}^{n+3}$ \\
$5.765(\mathrm{~b})$ & \\
\hline \hline & \\
\hline
\end{tabular}

region. The absence of high resolution supersonic beam experiments in this energy range makes assigning the spectra in this range particularly hard, although Trommsdorff ${ }^{19}$ has proposed $5.124 \mathrm{eV}$ as the spectral origin. Here we tentatively assign spectral progressions to the $v_{6}$-ring vibrational mode, which may be excited with the accompanying $\pi \pi^{*}$ excitation. In this case, the $v_{6}$-mode excited state frequency appears to drop from $55 \mathrm{meV}$ in the Band I region to between 45 and $50 \mathrm{meV}$ in this band. The present calculations also support a weak excitation to an additional ${ }^{1} \mathrm{~B}_{3 \mathrm{u}}$ state in this energy range.

\section{Band III (5.9-6.8 eV and 210-182 nm)}

The photoabsorption spectrum of Band III can be seen in Figure 2. Within this region, we find an absence of any structure. This suggests that the excited states have geometric configurations that differ significantly from the ground state, so that the excitation overlaps a potential energy surface that 
promotes restructure or dissociation. It is therefore expected that the excitation would trigger significant geometric relaxation upon excitation. Weber et al. ${ }^{25}$ suggested that the low energy side is dominated by a continuation of the ${ }^{1} \mathrm{~B}_{1 \mathrm{u}}$ progression, while forbidden ${ }^{1} \mathrm{~B}_{3 \mathrm{~g}}$ and ${ }^{1} \mathrm{~B}_{2 \mathrm{u}}$ states may gain intensity through vibronic coupling. The present TD-DFT calculations are consistent with this interpretation, although the FSCI calculations do not recover any states attributable to features in this energy range.

\section{E. Band IV and V (6.8-10.8 eV and 182-115 nm)}

The photoabsorption spectrum of Band IV $+\mathrm{V}$ is presented in Figure 5, with the present spectral assignments being contained in Table $\mathrm{V}$. At the TD-DFT level, the Band IV region of the spectrum is dominated by two $\pi \pi^{*}$ transitions to the ${ }^{1} \mathrm{~B}_{1 \mathrm{u}}$ $(7.24 \mathrm{eV})$ and ${ }^{1} \mathrm{~B}_{2 \mathrm{u}}(7.49 \mathrm{eV})$ states. Here most of the spectral features associated with the valence transitions are broad. An intense series of Rydberg features are also observed to lie above the valence bands, with these features being discussed in more detail below.

Rydberg features dominate the Band $\mathrm{V}$ region with the present spectral assignments being contained in Table VI. Here a series of intense Rydberg lines is observed. These lines lie above the weaker but dipole-allowed $\pi \pi^{*}$ transitions to a ${ }^{1} B_{2 u}$ $(9.35 \mathrm{eV})$ state. There are also a number of other valence states in this region which may gain some intensity through vibronic coupling.

\section{F. Rydberg bands}

pBQ displays a prominent Rydberg spectrum that can be seen in Figure 5, with a zoom-in being presented in Figure 6 to assist in observing the high detail contained within the 8.8$10.0 \mathrm{eV}$ spectral region. We reiterate that a summary of the experimental energies of those features, Rydberg assignments, and quantum defects can be found in Table VI. Brint et al. ${ }^{21}$ originally assigned these progressions based on a quantum defect analysis from the ketonic series. Both Weber et al. ${ }^{25}$ and Pou-Amérigo and co-workers ${ }^{24}$ have further suggested that the

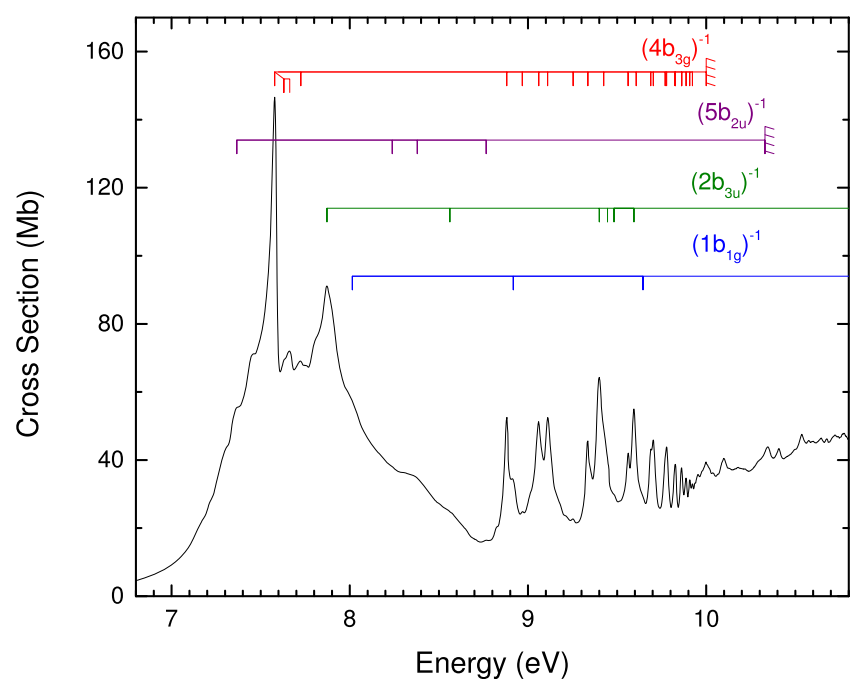

FIG. 5. Photoabsorption spectrum of $\mathrm{pBQ}$ in the 6.8-10.8 eV energy region $($ Band IV + V).
TABLE V. Prominent experimental features observed in the photoabsorption spectrum in the 6.8-10.8 eV Range (Bands IV + V). (b) Broad; (s) shoulder; (w) weak.

\begin{tabular}{|c|c|c|c|}
\hline Energy $(\mathrm{eV})$ & Assignment & Energy $(\mathrm{eV})$ & Assignment \\
\hline 7.217 & & 9.483 & $3 \mathrm{p} / \mathrm{d}\left(2 \mathrm{~b}_{3 \mathrm{u}}\right)^{-1}$ \\
\hline 7.259 & & 9.562 & $6 \mathrm{p} / \mathrm{d}\left(4 \mathrm{~b}_{3 \mathrm{~g}}\right)^{-1}$ \\
\hline $7.301(\mathrm{~s})$ & & 9.595 & $4 s\left(3 b_{3 u}\right)^{-1}$ \\
\hline $7.366(\mathrm{~s})$ & $3 \mathrm{~s}\left(5 \mathrm{~b}_{2 \mathrm{u}}\right)^{-1}$ & $9.607(\mathrm{~s})$ & $6 \mathrm{p} / \mathrm{d}\left(4 \mathrm{~b}_{3 \mathrm{~g}}\right)^{-1}$ \\
\hline 7.451 & & $9.626(\mathrm{~s})$ & \\
\hline 7.579 & $3 p\left(4 b_{3 g}\right)^{-1}$ & $9.645(\mathrm{~s})$ & $4 p\left(1 b_{1 g}\right)^{-1}$ \\
\hline 7.630 & $3 p\left(4 b_{3 g}\right)^{-1}+6_{0}^{1}$ & 9.689 & $7 \mathrm{p} / \mathrm{d}\left(4 \mathrm{~b}_{3 \mathrm{~g}}\right)^{-1}$ \\
\hline 7.663 & $3 \mathrm{p}\left(4 \mathrm{~b}_{3 \mathrm{~g}}\right)^{-1}+5_{0}^{1}$ & 9.703 & $7 \mathrm{p} / \mathrm{d}\left(4 \mathrm{~b}_{3 \mathrm{~g}}\right)^{-1}$ \\
\hline 7.725 & $3 p\left(4 b_{3 g}\right)^{-1}$ & $9.770(\mathrm{~s})$ & $8 \mathrm{p} / \mathrm{d}\left(4 \mathrm{~b}_{3 \mathrm{~g}}\right)^{-1}$ \\
\hline 7.811 & & 9.778 & $8 \mathrm{p} / \mathrm{d}\left(4 \mathrm{~b}_{3 \mathrm{~g}}\right)^{-1}$ \\
\hline 7.872 & $3 s\left(2 b_{3 u}\right)^{-1}$ & $9.826(b)$ & $9 \mathrm{p} / \mathrm{d}\left(4 \mathrm{~b}_{3 \mathrm{~g}}\right)^{-1}$ \\
\hline $8.014(\mathrm{~s})$ & $3 p\left(1 b_{1 g}\right)^{-1}$ & $9.862(b)$ & $10 \mathrm{p} / \mathrm{d}\left(4 \mathrm{~b}_{3 \mathrm{~g}}\right)^{-1}$ \\
\hline 8.238 & $3 \mathrm{p} / \mathrm{d}\left(5 \mathrm{~b}_{2 \mathrm{u}}\right)^{-1}$ & $9.887(b)$ & $11 \mathrm{p} / \mathrm{d}\left(4 \mathrm{~b}_{3 \mathrm{~g}}\right)^{-1}$ \\
\hline $8.310(w)$ & & $9.908(b)$ & \\
\hline 8.379 & $3 \mathrm{p} / \mathrm{d}\left(5 \mathrm{~b}_{2 \mathrm{u}}\right)^{-1}$ & $9.923(b)$ & \\
\hline $8.562(\mathrm{~s})$ & $3 \mathrm{p} / \mathrm{d}\left(2 \mathrm{~b}_{3 \mathrm{u}}\right)^{-1}$ & 9.938 & \\
\hline $8.652(w s)$ & & 9.949 & \\
\hline $8.710(w)$ & & 9.954 & \\
\hline 8.765 & $3 \mathrm{p} / \mathrm{d}\left(5 \mathrm{~b}_{2 \mathrm{u}}\right)^{-1}$ & 9.999 & \\
\hline 8.826 & & 10.039 & \\
\hline 8.881 & $4 \mathrm{p} / \mathrm{d}\left(4 \mathrm{~b}_{3 \mathrm{~g}}\right)^{-1}$ & 10.099 & \\
\hline 8.917 & $3 \mathrm{p}\left(1 \mathrm{~b}_{1 \mathrm{~g}}\right)^{-1}$ & 10.179 & \\
\hline 8.968 & $4 \mathrm{p} / \mathrm{d}\left(4 \mathrm{~b}_{3 \mathrm{~g}}\right)^{-1}$ & 10.217 & \\
\hline 9.013 & & $10.289(\mathrm{~s})$ & \\
\hline 9.060 & $4 \mathrm{p} / \mathrm{d}\left(4 \mathrm{~b}_{3 \mathrm{~g}}\right)^{-1}$ & 10.345 & \\
\hline 9.110 & $4 \mathrm{p} / \mathrm{d}\left(4 \mathrm{~b}_{3 \mathrm{~g}}\right)^{-1}$ & 10.408 & \\
\hline $9.160(\mathrm{~s})$ & & $10.494(\mathrm{~s})$ & \\
\hline $9.179(\mathrm{~s})$ & & 10.535 & \\
\hline $9.215(\mathrm{~s})$ & & 10.575 & \\
\hline 9.253 & $5 \mathrm{p} / \mathrm{d}\left(4 \mathrm{~b}_{3 \mathrm{~g}}\right)^{-1}$ & 10.600 & \\
\hline 9.336 & $5 \mathrm{p} / \mathrm{d}\left(4 \mathrm{~b}_{3 \mathrm{~g}}\right)^{-1}$ & 10.644 & \\
\hline $9.353(\mathrm{~s})$ & & 10.675 & \\
\hline 9.400 & $3 \mathrm{p} / \mathrm{d}\left(2 \mathrm{~b}_{3 \mathrm{u}}\right)^{-1}$ & 10.721 & \\
\hline $9.425(\mathrm{~s})$ & $5 \mathrm{p} / \mathrm{d}\left(4 \mathrm{~b}_{3 \mathrm{~g}}\right)^{-1}$ & 10.740 & \\
\hline $9.446(\mathrm{~s})$ & $3 \mathrm{p} / \mathrm{d}\left(2 \mathrm{~b}_{3 \mathrm{u}}\right)^{-1}$ & 10.773(b) & \\
\hline
\end{tabular}

Rydberg state assignments may include additional Rydberg series from the 4-outermost orbitals. Our assignments of the relevant Rydberg states are presented in Table VI, with that interpretation being derived from our calculations that provide insights into which Rydberg excitations are symmetry allowed and from a quantum defect analysis.

The high symmetry of $\mathrm{pBQ}$ leads to significant mixing of the atomic Rydberg contributions, in disagreement with the original purely ketonic Rydberg spectrum proposed by Brint et $a .^{21}$ Specifically, Brint et al. proposed the feature at $7.881 \mathrm{eV}$ as being a $\left(4 \mathrm{~b}_{3 \mathrm{~g}}\right)^{-1}(3 \mathrm{~d})$ excitation, with a large $\mathrm{d}$ state quantum defect of 0.47 . However, the transition to a $\left(4 b_{3 g}\right)^{-1}(3 d)$ state should be symmetry forbidden. We assign the transition to $\left(2 b_{3 u}\right)^{-1}(3 s)$ with a reasonable s-state quantum defect of 0.93 . This assignment is supported by the present TD-DFT calculation, which gives a transition to the $B_{3 u}$ state $(7.56 \mathrm{eV}, \mathrm{f}=0.033)$ with dominant configuration $\left[\left(2 b_{3 u}\right)^{-1}\left(9 a_{g}\right)\right]$. That observation also supports the earlier results from both CASPT2 studies ${ }^{24,25}$ that both ketonic and aromatic Rydberg progressions are observed for $\mathrm{pBQ}$. 
TABLE VI. Experimental energies (eV), Rydberg series assignment, and quantum defects for transitions observed in the photoabsorption spectrum.

\begin{tabular}{|c|c|c|c|}
\hline Energy $(\mathrm{eV})$ & Assignment & $\delta$ & Energy $(\mathrm{eV})^{21}$ \\
\hline $\operatorname{IE}\left(4 b_{3 g}\right)^{a}$ & $10.0 \mathrm{eV}$ & & \\
\hline 7.579 & $3 p$ & 0.629 & 7.579 \\
\hline 7.725 & $3 p$ & 0.554 & \\
\hline 8.881 & $4 \mathrm{p} / \mathrm{d}$ & 0.513 & 8.878 \\
\hline 8.968 & $4 \mathrm{p} / \mathrm{d}$ & 0.369 & \\
\hline 9.060 & $4 p / d$ & 0.196 & 9.049 \\
\hline 9.110 & $4 p / d$ & 0.090 & 9.109 \\
\hline 9.253 & $5 \mathrm{p} / \mathrm{d}$ & 0.732 & \\
\hline 9.336 & $5 \mathrm{p} / \mathrm{d}$ & 0.473 & 9.330 \\
\hline 9.425 & $5 \mathrm{p} / \mathrm{d}$ & 0.136 & 9.395 \\
\hline 9.562 & $6 \mathrm{p} / \mathrm{d}$ & 0.427 & 9.557 \\
\hline 9.607 & $6 \mathrm{p} / \mathrm{d}$ & 0.116 & 9.588 \\
\hline 9.689 & $7 \mathrm{p} / \mathrm{d}$ & 0.386 & 9.680 \\
\hline 9.703 & $7 \mathrm{p} / \mathrm{d}$ & 0.232 & 9.695 \\
\hline 9.770 & $8 \mathrm{p} / \mathrm{d}$ & 0.309 & 9.770 \\
\hline 9.778 & $8 \mathrm{p} / \mathrm{d}$ & 0.171 & \\
\hline $9.826^{\mathrm{b}}$ & $9 \mathrm{p} / \mathrm{d}$ & $0.38-0.15$ & 9.820 \\
\hline $9.862^{b}$ & $10 \mathrm{p} / \mathrm{d}$ & $0.38-0.00$ & 9.855 \\
\hline $9.887^{\mathrm{b}}$ & $11 \mathrm{p} / \mathrm{d}$ & $0.35-0.00$ & 9.882 \\
\hline $9.908^{b}$ & $n \mathrm{p} / \mathrm{d}$ & & 9.904 \\
\hline $9.923^{b}$ & $n \mathrm{p} / \mathrm{d}$ & & 9.917 \\
\hline $\operatorname{IE}\left(5 b_{2 u}\right)^{c}$ & $10.33 \mathrm{eV}$ & & \\
\hline 7.366 & $3 \mathrm{~s}$ & 0.857 & \\
\hline 8.238 & $3 \mathrm{p} / \mathrm{d}$ & 0.450 & \\
\hline 8.379 & $3 \mathrm{p} / \mathrm{d}$ & 0.359 & \\
\hline 8.765 & $3 \mathrm{p} / \mathrm{d}$ & 0.051 & \\
\hline $\operatorname{IE}\left(2 b_{3 u}\right)^{d}$ & $11.0 \mathrm{eV}$ & & \\
\hline 7.872 & $3 \mathrm{~s}$ & 0.914 & \\
\hline 8.562 & $3 \mathrm{p} / \mathrm{d}$ & 0.638 & \\
\hline 9.400 & $3 \mathrm{p} / \mathrm{d}$ & 0.084 & \\
\hline 9.446 & $3 \mathrm{p} / \mathrm{d}$ & 0.041 & \\
\hline 9.483 & $3 \mathrm{p} / \mathrm{d}$ & 0.005 & \\
\hline 9.595 & $4 \mathrm{~s}$ & 0.888 & \\
\hline $\operatorname{IE}\left(1 b_{1 g}\right)^{e}$ & $11.0 \mathrm{eV}$ & & \\
\hline 8.014 & $3 p$ & 0.865 & \\
\hline 8.917 & $3 p$ & 0.444 & \\
\hline 9.645 & $4 p$ & 0.831 & \\
\hline
\end{tabular}

${ }^{a}$ ns and nd Rydberg series are forbidden from this state.

$\mathrm{b}$ (Broad, asymmetric feature).

${ }^{c}$ np Rydberg series are forbidden from this state.

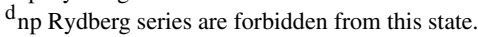

$\mathrm{e}_{\mathrm{ns}}$ and nd Rydberg series are forbidden from this state.

The higher members of the Rydberg series are more complicated to interpret. The TD-DFT calculation gives rise to a number of dipole-allowed excitations to high energy states. These states are built from a mixing of ketonic p-like contributions and d-like orbitals situated on the aromatic carbons. This mixing of the ketonic and aromatic contributions mixes the higher energy $\mathrm{p} / \mathrm{d}$ Rydberg states. We therefore assign the prominent Rydberg series to $\left(4 \mathrm{~b}_{3 \mathrm{~g}}\right)^{-1}(\mathrm{np} / \mathrm{nd})$ like transitions that possess a range of quantum defect values between 0.74 and 0.00 (see Table VI). It is noteworthy that the low-quantum number series show large splitting through Rydberg valence mixing. The higher Rydberg series members $(n>8)$ appear as asymmetric and broad spectral features, suggesting that multiple transitions occur within each experimental feature.

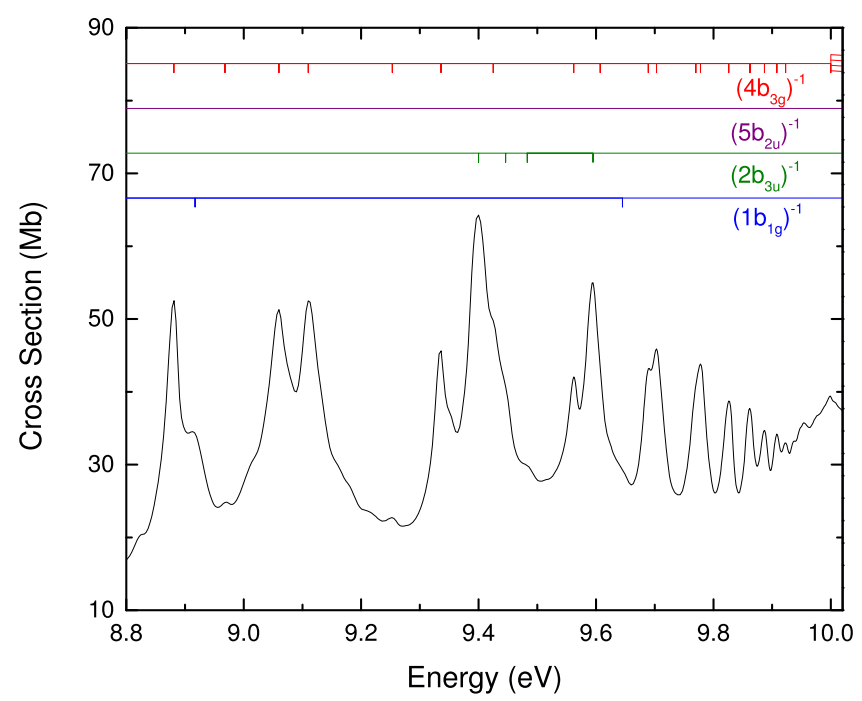

FIG. 6. Photoabsorption spectrum of pBQ in the 8.8-10.0 eV energy region showing the details of the Rydberg excitations.

The present measurement is the first to go above $10.0 \mathrm{eV}$. In this region, we can see evidence of the continuation of the aromatic, $\left(2 \mathrm{~b}_{3 \mathrm{u}}\right)$ and $\left(1 \mathrm{~b}_{1 \mathrm{~g}}\right)$, Rydberg series. The mixing of
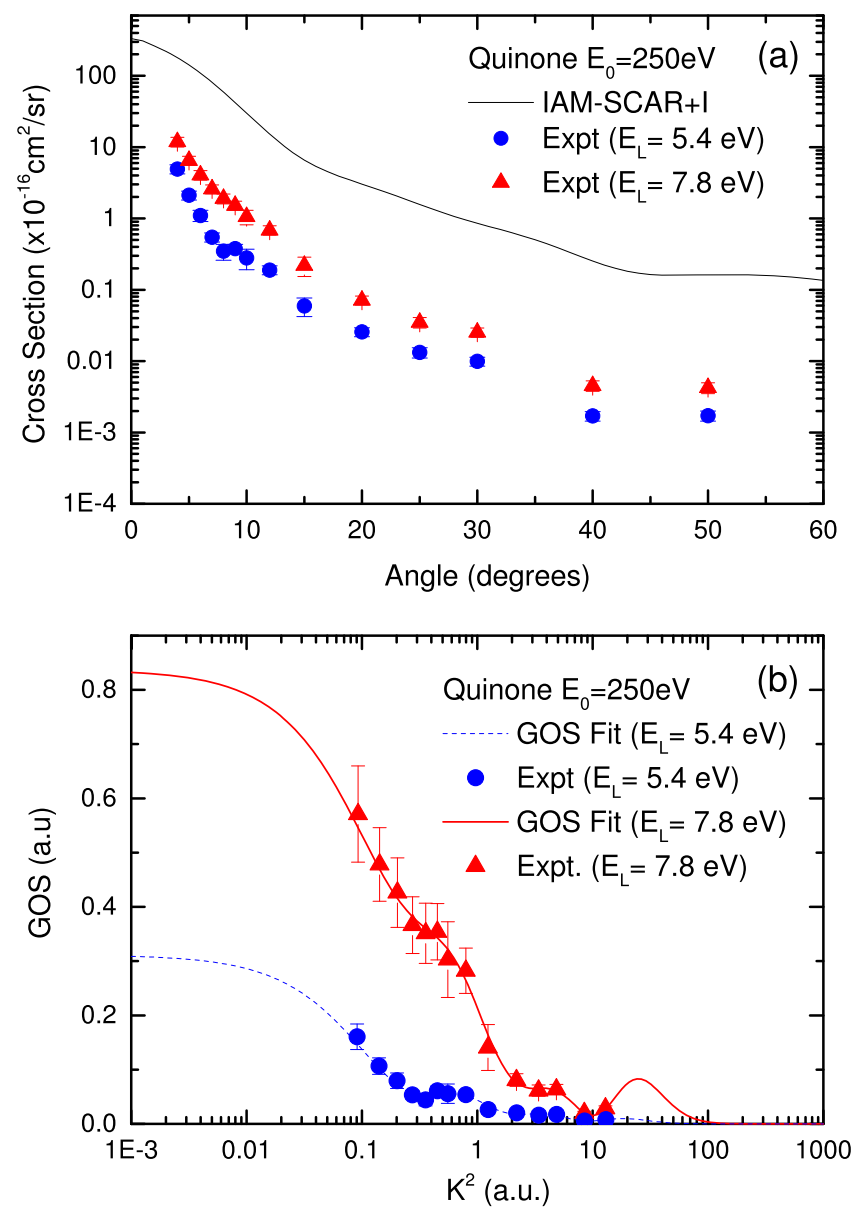

FIG. 7. (a) Differential cross sections (DCSs) for electron scattering from $\mathrm{pBQ}$ at $250 \mathrm{eV}$ impact energy. Theoretical elastic scattering DCSs were obtained at the IAM-SCAR + I level. Experimental inelastic DCS for excitation of Band II $\left(\mathrm{E}_{\mathrm{L}}=5.4 \mathrm{eV}\right)$ and the unresolved Bands IV $+\mathrm{V}\left(\mathrm{E}_{\mathrm{L}}=7.8 \mathrm{eV}\right)$. (b) Experimental generalized oscillator strengths (GOSs) for excitation of Band II and the unresolved Bands IV + V. Also shown are the GOS fitting functions. See text for further details. 
Rydberg (s,p,d) and valence states, coupled with the ionization potentials of the $\left(2 b_{3 u}\right)$ and $\left(1 b_{1 g}\right)$ states being unresolved, makes definitive assignments of these Rydberg states difficult at the present time. We do, however, point out that the existence of these Rydberg states, lying above the ionization potentials of both ketonic orbitals, provides further evidence that supports the existence of the aromatic Rydberg series, and gives additional weight to our assignment of the lower-lying states to the aromatic Rydberg progressions.

\section{G. Differential cross sections and oscillator strengths for some of the excitation processes.}

Elastic differential cross sections calculated at the IAMSCAR + I level and inelastic differential cross sections derived from measured electron energy loss spectra are presented in Figure 7, and tabulated in Table VII. The cross section for elastic scattering calculated within the IAM-SCAR + I level is quite large, reflecting the significant size of $\mathrm{pBQ}$. The inelastic DCSs are strongly forward peaked, characteristic of the dipole-allowed transitions contained within the unresolved experimental bands. These DCSs have been converted to GOSs that are also presented in the same figure. Here the GOS fitting procedure allows the determination of an experimental optical oscillator strength (OOS) for the excitation of Band II and the unresolved Bands IV $+\mathrm{V}$. Note that the unresolved Band IV $+\mathrm{V}$ is predominantly made of Band IV contributions, with a partial contribution from some states found in Band V. In this case, the remaining contribution from states found in Band V becomes inseparable from the contribution from the ionization continuum. Those experimental OOSs are compared against our present calculated values and previously reported values from the literature in Table VIII. To facilitate the comparison between the theoretical and experimental values, only states that can be assigned within the energy region recovered experimentally are included in the summation of the theoretical bands. Here we find reasonable agreement between our experimentally derived values, the earlier OOS determined from photoabsorption measurements, and the OOS calculated at the TD-DFT level (when summed over unresolved features). Interestingly, both of the CASSCF calculations recover OOS intensity for Band II that exceeds both the experimental and TD-DFT calculated intensities. For the unresolved Band IV $+\mathrm{V}$, the present and previous calculations perform well when compared to the experimental observations. The OOS obtained with the FSCI calculations are also presented in Table VIII. Here we can see that for Band II, both of the FSCI calculations give consistent OOS values with respect to the basis size, although they are larger than the experimental and other calculated values. This consistency suggests that within the FSCI framework, the low-lying excited states may be well described with the smaller basis. In Band IV, we see that the smaller basis gives a larger OOS than that from the larger basis. Specifically, we observe that expanding the basis to include more diffuse $\mathrm{p}$-like functions improves the description of the Rydberg-valence mixing. This allows these higher-lying states to lower in excitation energy and possess reduced OOSs that are more consistent with the experimental and other calculated values.

\section{H. MOBSCl framework for the scattering calculations}

The photoabsorption and energy loss spectra provide the foundation for constructing and assessing the building of a minimal orbital basis for the single-excitation configuration interaction (MOBSCI) framework that is required for performing electron scattering calculations using the Schwinger multichannel method with pseudopotentials (SMCPPs). ${ }^{33}$ The FSCI calculations presented in Tables I and II show very similar spectra for the low-lying states, indicating that the chosen Cartesian Gaussian basis is appropriate for these states. Typically the MOBSCI framework is constructed to best approximate the FSCI calculation, while still allowing the SMCPP scattering calculations to be computationally tractable (typically of the order of 100 open scattering channels). In this respect, $\mathrm{pBQ}$ is a particularly problematic target for building such a MOBSCI basis. As a matter of fact, pBQ presents a number of low lying states which must be well described in

TABLE VII. Differential cross sections for $\mathrm{pBQ}$ at $\mathrm{E}_{0}=250 \mathrm{eV}$. The elastic scattering DCS is calculated using the IAM-SCAR + I method. The experimental inelastic DCSs are for Band II and the unresolved Bands IV + V.

\begin{tabular}{|c|c|c|c|c|c|}
\hline \multirow{2}{*}{$\begin{array}{l}\text { Angle } \\
\left({ }^{\circ}\right)\end{array}$} & \multirow{2}{*}{$\begin{array}{c}\text { Elastic DCS } \\
\left(10^{-16} \mathrm{~cm}^{2} / \mathrm{sr}\right)\end{array}$} & \multicolumn{2}{|c|}{ Band II $\left(\mathrm{E}_{\mathrm{L}}=5.4 \mathrm{eV}\right)$} & \multicolumn{2}{|c|}{ Band IV + V $\left(\mathrm{E}_{\mathrm{L}}=7.8 \mathrm{eV}\right)$} \\
\hline & & $\operatorname{DCS}\left(10^{-16} \mathrm{~cm}^{2} / \mathrm{sr}\right)$ & Error $(\%)$ & $\operatorname{DCS}\left(10^{-16} \mathrm{~cm}^{2} / \mathrm{sr}\right)$ & Error $(\%)$ \\
\hline 4 & 179 & 4.93 & 15 & 11.9 & 16 \\
\hline 5 & 141 & 2.11 & 14 & 6.50 & 14 \\
\hline 6 & 109 & 1.10 & 18 & 4.07 & 15 \\
\hline 7 & 81.2 & 0.55 & 14 & 2.58 & 14 \\
\hline 8 & 59.3 & 0.35 & 25 & 1.91 & 16 \\
\hline 9 & 42.5 & 0.38 & 15 & 1.52 & 15 \\
\hline 10 & 29.9 & 0.28 & 32 & 1.06 & 23 \\
\hline 12 & 15.1 & 0.19 & 14 & 0.69 & 15 \\
\hline 15 & 6.58 & 0.059 & 29 & 0.22 & 30 \\
\hline 20 & 3.02 & 0.026 & 14 & 0.071 & 14 \\
\hline 25 & 1.58 & 0.013 & 16 & 0.035 & 17 \\
\hline 30 & 0.86 & 0.0099 & 14 & 0.025 & 15 \\
\hline 40 & 0.25 & 0.0017 & 15 & 0.0045 & 17 \\
\hline 50 & 0.16 & 0.0017 & 16 & 0.0042 & 17 \\
\hline
\end{tabular}


TABLE VIII. Experimentally derived optical oscillator strengths for some of the unresolved electronic states. Also presented are corresponding theoretical oscillator strengths summed over the unresolved states recovered in the experimental bands. See text for further details.

\begin{tabular}{|c|c|c|c|c|c|c|c|}
\hline Feature & Present -OOS & $\begin{array}{l}\text { Photoabs. } \\
\text { Brint } \text { et al. }\end{array}$ & TD-DFT & $\begin{array}{l}\text { FSCI/ } \\
5 \mathrm{~s} 5 \mathrm{p} 2 \mathrm{~d}\end{array}$ & $\begin{array}{l}\text { FSCI/ } \\
5 \mathrm{~s} 6 \mathrm{p} 2 \mathrm{~d}\end{array}$ & CASPT 225 & CASPT2 24 \\
\hline Band I & $\ldots$ & $0.005 \pm 0.001$ & 0.000 & & & $\ldots$ & $\ldots$ \\
\hline Band II & $0.31 \pm 0.01$ & $0.44 \pm 0.05$ & 0.315 & 1.070 & 1.070 & 0.637 & 0.616 \\
\hline Band III & & & 0.014 & & & 0.012 & $\ldots$ \\
\hline Band IV + $\mathrm{V}^{\mathrm{a}}$ & $0.83 \pm 0.04$ & $0.81 \pm 0.10$ & $0.969^{\mathrm{b}}$ & 1.082 & 0.872 & $0.842^{\mathrm{c}}$ & $0.782^{\mathrm{b}}$ \\
\hline Sum (I-V) & $1.14 \pm 0.04$ & $1.26 \pm 0.10$ & 1.298 & & & 1.491 & 1.398 \\
\hline
\end{tabular}

a Unresolved combination of Band IV + V captured in the experiment.

${ }^{\mathrm{b}}$ States with energies up to $9.00 \mathrm{eV}$ in Band $\mathrm{V}$ are included in the summed OOS.

${ }^{\mathrm{c}}$ All reported states included in OOS sum (energies up to $8.39 \mathrm{eV}$ ).

the MOBSCI framework, while there is also the $\pi \pi^{*}$ excitations that produce an intense feature in Band IV. It is therefore challenging to balance the MOBSCI framework so that it provides a good description of the important low-lying states, but also allows the inclusion of excitation channels that adequately describe the strong higher-energy excitations. Our efforts to develop and implement the MOBSCI strategy for sophisticated electron scattering calculations are ongoing and it aims to include all the FSCI states (below $9 \mathrm{eV}$ ) of Tables I and II in the scattering calculation.

\section{CONCLUSIONS}

We have presented an experimental and theoretical investigation into the electron-impact excitation of parabenzoquinone. Our high resolution synchrotron photoabsorption measurements allow the identification of previously unresolved experimental features. This permits a re-assessment and re-assignment of many states, particularly relating to the Rydberg series. Differential cross sections were derived from electron energy loss spectra. Further, a generalised oscillator strength analysis demonstrated that the combination of experimental electron energy loss spectra measurements, IAMSCAR + I elastic scattering differential scattering cross section calculations, and quantum chemical calculations yielded a consistent quantum chemical interpretation of the pBQ structure. Through this consistency, we have confidence in both the reported cross sections, and the quantum chemical picture proposed. This investigation also identified challenges in developing a strategy to include the multichannel coupling effects in the scattering calculations that will be carried out with the SMCPP method within the scope of the MOBSCI approximation. Overcoming those challenges, and undertaking further low-energy electron scattering experiments, will form an essential part of developing complete cross section sets for this important molecular species.

\section{ACKNOWLEDGMENTS}

M.M. acknowledges the Portuguese National Funding Agency FCT-MCTES through PD/BD/106038/2015 and together with PLV the research Grant No. UID/FIS/00068/ 2013. This work was also supported by Radiation Biology and Biophysics Doctoral Training Programme (RaBBiT, PD/00193/2010); UID/Multi/04378/2013 (UCIBIO). G.G. acknowledges partial financial support from the Spanish Ministerio de Economia, Industria y Competitividad (Project No. FIS2016-8440), and the EU Project No. FP7-ITN-ARGENT608163. The authors wish to acknowledge the beam time at the ASTRID2 synchrotron at ISA, Aarhus University, Denmark. We also acknowledge the financial support provided by the European Community's Seventh Framework Programme (FP7/2007-2013) CALIPSO under Grant Agreement No. 312284. M.J.B. acknowledges the Australian Research Council for some financial support. M.T.N.V. and M.A.P.L. acknowledge financial support from FAPESP, while R.F.C., M.T.N.V., M.H.F.B., and M.A.P.L. acknowledge financial support from CNPq.

${ }^{1}$ A. Zouni, H.-T. Witt, J. Kern, P. Fromme, N. Krauss, W. Saenger, and P. Orth, Nature 409, 739 (2001).

${ }^{2}$ M. Hambourger, G. F. Moore, D. M. Kramer, D. Gust, A. L. Moore, and T. A. Moore, Chem. Soc. Rev. 38, 25 (2009).

${ }^{3}$ O. Yehezkeli, R. Tel-Vered, J. Wasserman, A. Trifonov, D. Michaeli, R. Nechushtai, and I. Willner, Nat. Commun. 3, 742 (2012).

${ }^{4}$ B. Huskinson, M. P. Marshak, C. Suh, S. Er, M. R. Gerhardt, C. J. Galvin, X. Chen, A. Aspuru-Guzik, R. G. Gordon, and M. J. Aziz, Nature 505, 195 (2014).

${ }^{5}$ Y. Ding and G. Yu, Angew. Chem., Int. Ed. 55, 4772 (2016).

${ }^{6}$ D. R. Choudhury, Environ. Sci. Technol. 16, 102 (1982).

${ }^{7}$ T. Itoh, Chem. Rev. 95, 2351 (1995).

${ }^{8}$ B. Ómarsson and O. Ingólfsson, Phys. Chem. Chem. Phys. 15, 16758 (2013)

${ }^{9}$ D. Dougherty and S. P. McGlynn, J. Am. Chem. Soc. 99, 3234 (1977).

${ }^{10}$ J. F. Stanton, K. W. Sattelmeyer, J. Gauss, M. Allan, T. Skalicky, and T. Bally, J. Chem. Phys. 115, 1 (2001).

${ }^{11}$ C. R. Brundle, M. B. Robin, and N. A. Kuebler, J. Am. Chem. Soc. 94, 1466 (1972).

${ }^{12}$ L. Åsbrink, G. Bieri, C. Fridh, E. Lindholm, and D. P. Chong, Chem. Phys. 43, 189 (1979).

${ }^{13}$ N. Kishimoto, K. Okamura, and K. Ohno, J. Chem. Phys. 120, 11062 (2004).

${ }^{14}$ K. Piech, T. Bally, T. Ichino, and J. Stanton, Phys. Chem. Chem. Phys. 16, 2011 (2014).

${ }^{15}$ J. M. Hollas, Spectrochimica Acta 20, 1563 (1964).

${ }^{16}$ N. Ohta, I. Yamazaki, M. Sanekata, I. Suzuka, and O. Sekiguchi, J. Phys. Chem. 97, 7857 (1993).

${ }^{17}$ G. Ter Horst and J. Kommandeur, Chem. Phys. 44, 287 (1979).

${ }^{18}$ A. Sadô, Bull. Chem. Soc. Jpn. 35, 1520 (1962).

${ }^{19}$ H. P. Trommsdorff, J. Chem. Phys. 56, 5358 (1972).

${ }^{20}$ H. P. Trommsdorff and J. Kahane-Paillous, Spectrochim. Acta A 23, 1661 (1967).

${ }^{21}$ P. Brint, J.-P. Connerade, P. Tsekeris, A. Bolovinos, and A. Baig, J. Chem. Soc., Faraday Trans. 2 82, 367 (1986).

${ }^{22}$ A. Kuboyama, S. Matsuzaki, H. Takagi, and H. Arano, Bull. Chem. Soc. Jpn. 47, 1604 (1974).

${ }^{23}$ P. Brint, P. Tsekeris, A. Bolovinos, and C. Kosmidis, J. Chem. Soc., Faraday Trans. 2 85, 177 (1989). 
${ }^{24}$ R. Pou-Amérigo, M. Merchán, and E. Ortí, J. Chem. Phys. 110, 9536 (1999).

${ }^{25}$ J. Weber, K. Malsch, and G. Hohlneicher, Chem. Phys. 264, 275 (2001).

${ }^{26}$ D. A. Horke, Q. Li, L. Blancafort, and J. R. R. Verlet, Nat. Chem. 5, 711 (2013).

${ }^{27}$ L. G. Christophorou, J. G. Carter, and A. A. Christodoulides, Chem. Phys. Lett. 3, 237 (1969).

${ }^{28}$ P. M. Collins, L. G. Christophorou, E. L. Chaney, and J. G. Carter, Chem. Phys. Lett. 4, 646 (1970).

${ }^{29}$ C. D. Cooper, W. T. Naff, and R. N. Compton, J. Chem. Phys. 63, 2752 (1975).

${ }^{30}$ M. Allan, Chem. Phys. 84, 311 (1984).

${ }^{31}$ M. Allan, Chem. Phys. 81, 235 (1983).

${ }^{32}$ D. B. Jones, E. Ali, C. G. Ning, J. Colgan, O. Ingólfssson, D. H. Madison, and M. J. Brunger, J. Chem. Phys. 145, 164306 (2016).

${ }^{33}$ R. F. da Costa, M. T. do N. Varella, M. H. F. Bettega, and M. A. P. Lima, Eur. Phys. J. D 69, 159 (2015).

${ }^{34}$ R. F. da Costa, E. M. de Oliveira, M. H. F. Bettega, M. T. do N. Varella, D. B. Jones, M. J. Brunger, F. Blanco, R. Colmenares, P. Limão-Vieira, G. García, and M. A. P. Lima, J. Chem. Phys. 142, 104304 (2015).

${ }^{35}$ R. F. da Costa, M. T. do N. Varella, M. H. F. Bettega, R. F. C. Neves, M. C. A. Lopes, F. Blanco, G. García, D. B. Jones, M. J. Brunger, and M. A. P. Lima, J. Chem. Phys. 144, 124310 (2016).

${ }^{36}$ D. B. Jones, G. B. da Silva, R. F. C. Neves, H. V. Duque, L. Chiari, E. M. de Oliveira, M. C. A. Lopes, R. F. da Costa, M. T. do N. Varella, M. H. F. Bettega, M. A. P. Lima, and M. J. Brunger, J. Chem. Phys. 141, 074314 (2014)

${ }^{37}$ D. B. Jones, R. F. da Costa, M. T. do N. Varella, M. H. F. Bettega, M. A. P. Lima, F. Blanco, G. García, and M. J. Brunger, J. Chem. Phys. 144, 144303 (2016).

${ }^{38}$ S. Eden, P. Limão-Vieira, S. V. Hoffmann, and N. J. Mason, Chem. Phys. 323, 313 (2006).

${ }^{39}$ M. H. Palmer, T. Ridley, S. V. Hoffmann, N. C. Jones, M. Coreno, M. de Simone, C. Grazioli, M. Biczysko, A. Baiardi, and P. Limão-Vieira, J. Chem. Phys. 142, 134302 (2015).

${ }^{40}$ M. J. Brunger and P. J. O. Teubner, Phys. Rev. A 41, 1413 (1990).

${ }^{41}$ S. J. Cavanagh and B. Lohmann, J. Phys. B: At., Mol. Opt. Phys. 32, L261 (1999).

${ }^{42}$ F. Blanco and G. García, J. Phys. B: At., Mol. Opt. Phys. 42, 145203 (2009).

${ }^{43}$ F. Blanco and G. García, Phys. Lett. A 330, 230 (2004).

${ }^{44}$ F. Blanco and G. García, Chem. Phys. Lett. 635, 321 (2015).

${ }^{45}$ P. Palihawadana, J. Sullivan, M. Brunger, C. Winstead, V. McKoy, G. García, F. Blanco, and S. Buckman, Phys. Rev. A 84, 062702 (2011).
${ }^{46}$ L. R. Hargreaves, J. R. Brunton, A. Prajapati, M. Hoshino, F. Blanco, G. García, S. J. Buckman, and M. J. Brunger, J. Phys. B: At., Mol. Opt. Phys. 44, 045207 (2011).

${ }^{47}$ H. Kato, T. Asahina, H. Masui, M. Hoshino, H. Tanaka, H. Cho, O. Ingólfsson, F. Blanco, G. García, S. J. Buckman, and M. J. Brunger, J. Chem. Phys. 132, 074309 (2010).

${ }^{48}$ M. J. Brunger, Int. Rev. Phys. Chem. 36, 333 (2017).

${ }^{49}$ E. N. Lassettre, J. Chem. Phys. 43, 4479 (1965).

${ }^{50}$ L. Vriens, Phys. Rev. 160, 100 (1967).

${ }^{51}$ H. Kawahara, H. Kato, M. Hoshino, H. Tanaka, and M. J. Brunger, Phys. Rev. A 77, 012713 (2008).

${ }^{52}$ H. Kawahara, D. Suzuki, H. Kato, M. Hoshino, H. Tanaka, O. Ingólfssson, L. Campbell, and M. J. Brunger, J. Chem. Phys. 131, 114307 (2009).

${ }^{53}$ H. Kato, M. Hoshino, H. Tanaka, P. Limão-Vieira, O. Ingólfsson, L. Campbell, and M. J. Brunger, J. Chem. Phys. 134, 134308 (2011).

${ }^{54}$ F. Ferreira da Silva, E. Lange, P. Limão-Vieira, N. C. Jones, S. V. Hoffmann, M.-J. Hubin-Franskin, J. Delwiche, M. J. Brunger, R. F. C. Neves, M. C. A. Lopes, E. M. de Oliveira, R. F. da Costa, M. T. d. N. Varella, M. H. F. Bettega, F. Blanco, G. García, M. A. P. Lima, and D. B. Jones, J. Chem. Phys. 143, 144308 (2015).

${ }^{55}$ H. Tanaka, M. J. Brunger, L. Campbell, H. Kato, M. Hoshino, and A. R. P. Rau, Rev. Mod. Phys. 88, 025004 (2016).

${ }^{56}$ C. Lee, W. Yang, and R. G. Parr, Phys. Rev. B 37, 785 (1988).

${ }^{57}$ T. H. Dunning, J. Chem. Phys. 90, 1007 (1989).

${ }^{58}$ R. A. Kendall, T. H. Dunning, and R. J. Harrison, J. Chem. Phys. 96, 6796 (1992).

${ }^{59}$ M. E. Casida, J. Mol. Struct.: THEOCHEM 914, 3 (2009).

${ }^{60}$ R. Bauernschmitt and R. Ahlrichs, Chem. Phys. Lett. 256, 454 (1996).

${ }^{61}$ M. J. Frisch, G. W. Trucks, H. B. Schlegel, G. E. Scuseria, M. A. Robb, J. R. Cheeseman, G. Scalmani, V. Barone, B. Mennucci, G. A. Petersson, H. Nakatsuji, M. Caricato, X. Li, H. P. Hratchian, A. F. Izmaylov, J. Bloino, G. Zheng, J. L. Sonnenberg, M. Hada, M. Ehara, K. Toyota, R. Fukuda, J. Hasegawa, M. Ishida, T. Nakajima, Y. Honda, O. Kitao, H. Nakai, T. Vreven, J. A. Montgomery, J. E. Peralta, F. Ogliaro, M. Bearpark, J. J. Heyd, E. Brothers, K. N. Kudin, V. N. Staroverov, R. Kobayashi, J. Normand, K. Raghavachari, A. Rendell, J. C. Burant, S. S. Iyengar, J. Tomasi, M. Cossi, N. Rega, J. M. Millam, M. Klene, J. E. Knox, J. B. Cross, V. Bakken, C. Adamo, J. Jaramillo, R. Gomperts, R. E. Stratmann, O. Yazyev, A. J. Austin, R. Cammi, C. Pomelli, J. W. Ochterski, R. L. Martin, K. Morokuma, V. G. Zakrzewski, G. A. Voth, P. Salvador, J. J. Dannenberg, S. Dapprich, A. D. Daniels, Ö. Farkas, J. B. Foresman, J. V. Ortiz, J. Cioslowski, and D. J. Fox, Gaussian 09, Revision B.01, Gaussian, Inc., 2010. 